\title{
Invited review: Use of infrared technologies for the assessment of dairy products-Applications and perspectives
}

\author{
M. De Marchi, ${ }^{* 1}$ M. Penasa, ${ }^{*}$ A. Zidi, $†$ and C. L. Manuelian* \\ *Department of Agronomy, Food, Natural Resources, Animals and Environment, and \\ †Department of Animal Medicine, Production and Health, University of Padova, Viale dell'Università 16, 35020 Legnaro (PD), Italy
}

\begin{abstract}
Dairy products are important sources of nutrients for human health and in recent years their consumption has increased worldwide. Therefore, the food industry is interested in applying analytical technologies that are more rapid and cost-effective than traditional laboratory analyses. Infrared spectroscopy accomplishes both criteria, making real-time determination feasible. However, it is crucial to ensure that prediction models are accurate before their implementation in the dairy industry. In the last $5 \mathrm{yr}$, several papers have investigated the feasibility of mid- and near-infrared spectroscopy to determine chemical composition and authenticity of dairy products. Most studies have dealt with cheese, and few with yogurt, butter, and milk powder. Also, the use of near-infrared (in reflectance or transmittance mode) has been more prevalent than mid-infrared spectroscopy. This review summarizes recent studies on infrared spectroscopy in dairy products focusing on difficult to determine chemical components such as fatty acids, minerals, and volatile compounds, as well as sensory attributes and ripening time. Promising equations have been developed despite the low concentration or the absence of specific absorption bands (or both) for these compounds.
\end{abstract}

Key words: cheese, infrared spectroscopy, milk powder, yogurt

\section{INTRODUCTION}

Milk and dairy products are a valuable source of important nutrients for human beings such as protein, fatty acids (FA), minerals (e.g., calcium, phosphorus, magnesium), vitamins $\left(\mathrm{B}_{2}, \mathrm{~B}_{12}, \mathrm{~A}, \mathrm{~B}_{6}\right.$, and $\left.\mathrm{D}\right)$, and bioactive peptides (Miller et al., 2007; Walther et al., 2008;

Received June 13, 2018.

Accepted August 20, 2018.

${ }^{1}$ Corresponding author: massimo.demarchi@unipd.it
FAO, 2013). In the last $10 \mathrm{yr}$, great attention has been paid to the development of innovative dairy products that better fit consumers' desires, which are mainly related to functional aspects important for human nutrition and health. Moreover, the implementation of new technologies (e.g., microfiltration, ultrafiltration, nanofiltration, and reverse osmosis) at the dairy manufacturing level, especially in relation to dairy industry side-products such as whey and whey-derived components, has led to the development of new manufacturing processes aiming to recover nutritional compounds.

Concerning dairy products and human nutrition, several health food authorities recommend paying attention to fat daily intake and the type of FA; for example, they suggest reducing SFA and avoiding trans FA because of their connection with the risk of cancer and cardiovascular, inflammatory, and autoimmune diseases (Simopoulos, 2002; WHO, 2015; FSA, 2016). An additional issue is related to minerals: Ca dietary intake, which derives mainly from milk and dairy products (60 to 70\%), is essential for bone and teeth health (Walther et al., 2008; Bonjour et al., 2009), whereas high $\mathrm{Na}$ intake has been related to an increase of the risk of cardiovascular diseases (Aburto et al., 2013). Some of these scientific evidences have become official guidelines in some countries such as the mandatory labeling regulation that compels the declaration of salt and SFA on the product label in Europe (EU, 2011).

Therefore, several analytical technologies have been applied in the past 2 decades to provide new opportunities in dairy manufacturing processes related to increase efficiency, improve profitability, and enhance quality. These technologies are mainly related to on-line and in-line solutions that can be applied to different stages of manufacturing dairy process. Overall, the in-line applications are limited, but they refer to process control through the monitoring of crucial traits (e.g., recording of real-time production data) that allow rapid action and cost saving; the on-line applications are mainly related to end product labeling specification based on the development of prediction models using reference methods. 
One of the most relevant technologies widely used in dairy industry for raw material, process control, and end product specification analysis is infrared spectroscopy. This technique is based on the analysis of the interaction between electromagnetic waves and matter, and electromagnetic radiation comprises different regions according to the different wavelengths (O'Donnell et al., 2014). The main spectra regions involved at dairy industry level are the near-infrared (NIR; 800 to 2,500 $\mathrm{nm}$ ) and the mid-infrared (MIR; 2,500 to 25,000 $\mathrm{nm})$ regions. Several authors have reviewed the basis of NIR and MIR spectroscopy (Fagan and O'Donnell, 2007; Griffiths, 2010; De Marchi et al., 2014); however, information about the on-line applications of NIR and MIR spectroscopy is lacking.

Mid-infrared spectroscopy is widely used in raw milk by processors for standardization purposes before milk transformation, by dairy industry for milk payment, and by farmers, technicians, and breeding companies which used several milk phenotypes; these applications have been reviewed by De Marchi et al. (2014) and will not be discussed further. On the other side, the use of MIR and NIR technologies to determine quality features of dairy products has gained interest in the last years and a review to summarize the outcomes from the scientific literature is appropriate. Therefore, the aim of this paper was to review the literature on infrared spectroscopy applied to dairy products available online between 2013 and 2017.

\section{ORIGIN OF THE PAPERS AND OVERVIEW}

Papers included in the present review were retrieved from Scopus (www.scopus.com) and ISI Web of Science (www.webofknowledge.com) databases. Papers that dealt with fluid milk were not considered here. Table 1 summarizes the on-line applications of infrared technologies of the selected papers. Some of the on-line applications are currently used in the industry, whereas others were developed mainly for research purposes. The applications referred to cheese, curd, butter, milk powder, and yogurt, with the main purpose of assessing chemical composition (e.g., gross composition, and mineral and FA profile), authentication, and process control of the products. Most applications reviewed in the present paper have been developed for cheese and curd products; several studies have investigated chemical traits and others have focused on authentication approaches combining feeding regimen, geographic region, ripening time, and storage temperature information. The FA composition (e.g., trans FA and palm oil) and authentication issues have been also the most recent and relevant applications of infrared technologies in butter production.

The authors' key words were extracted adapting the Bibliometrix package (Aria and Cuccurullo, 2017) for R v. 3.4 software (R Core Team, 2018), producing the network of the 15 more recurrent key words weighed by their frequency (Figure 1). The closer 2 words are

Table 1. Overview of the use of infrared technology in dairy products from the literature available online between 2013 and 2017

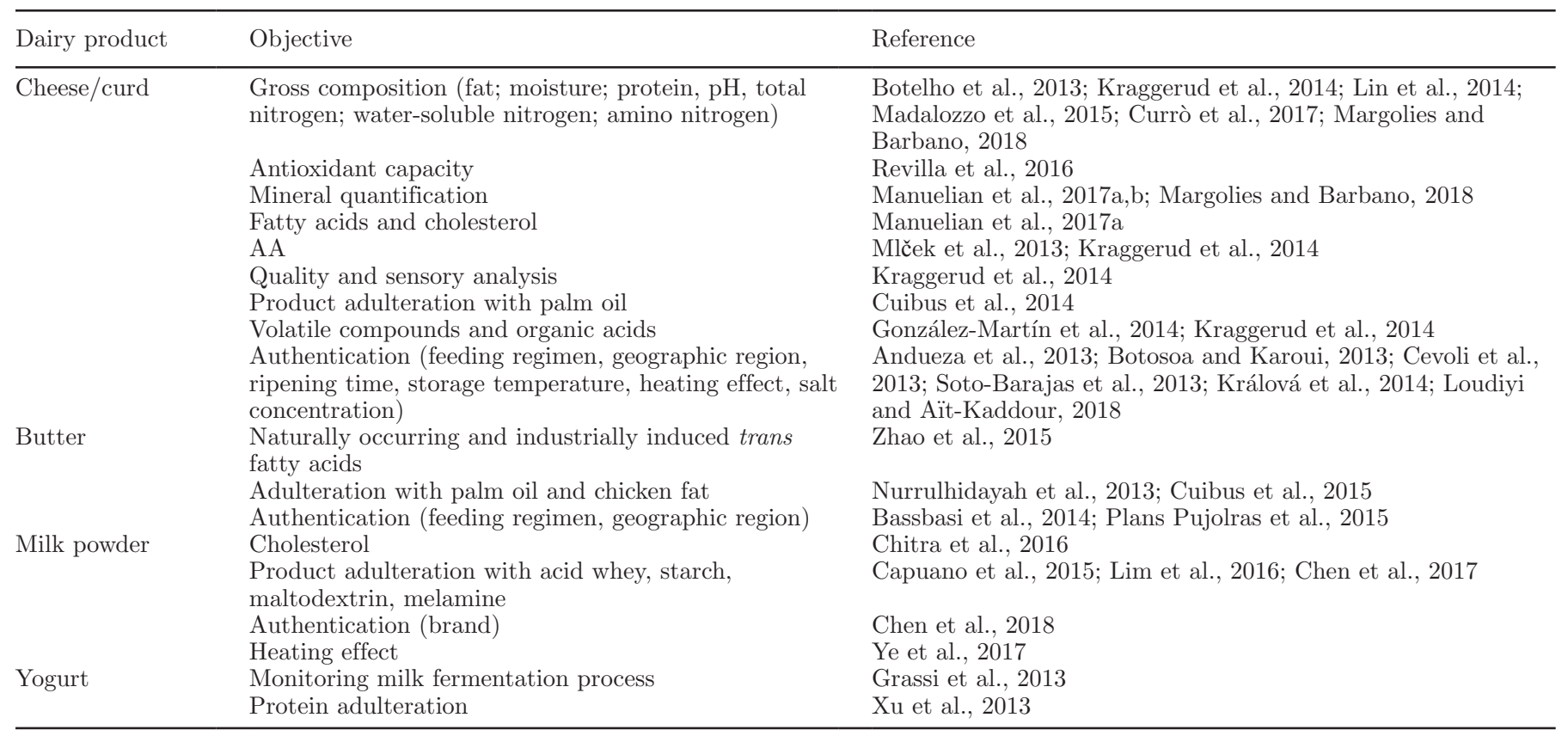


represented in the map, the stronger is their relationship. The total number of key words retrieved was 65 . The key word "near-infrared spectroscopy" was the most repeated (11 times). The papers were from 14 different countries, and Italy and China had the greatest number of published papers (5 each). Almost all manuscripts from Italy dealt with cheese, and those from China were mainly about milk powder. Moreover, half of the research papers dealing with cheese were from 3 European countries (Italy, Spain, and France), which are known and appreciated worldwide for their cheese production, quality, and diversity.

\section{INFRARED TECHNOLOGIES}

Several MIR and NIR spectroscopy instruments, which are both based on the Beer-Lambert law (McKenna, 2001), have been used to predict traits in dairy products. In the reviewed studies, instruments that worked at the MIR wavelength used the Fourier transformation, whereas not all instruments that worked in the NIR wavelength used the Fourier transformation and most of them worked in reflectance mode. The spectrum obtained for cheese, milk, and other complex matrixes results from the interaction of the vibrations of the chemical bonds from all constituents (e.g., FA, proteins, and lactose) and not only from one (Soyeurt et al., 2006). The analysis with MIR spectroscopy provides information on fundamental vibrations and associated rotational-vibration structure in the wavenumber range from 4,000 to $700 \mathrm{~cm}^{-1}$ (Cevoli et al., 2013). Cheese samples have to be ground (Cuibus et al., 2014; Kraggerud et al., 2014) or liquated (Margolies and Barbano, 2018) to be scanned with a MIR spectroscopy instrument. On the other hand, NIR spectrum results from the overtones and combinations of the fundamental frequencies in the MIR region detected in the spectral range from 750 to 2,500 nm (McKenna, 2001). Moreover, Margolies and Barbano (2018) reported that once the cheese sample is liquated, there is the opportunity to centrally prepare the calibration model and provide calibration samples to the factories, similarly to what is generally done for milk. This would avoid developing the calibration in each factory, which on the contrary is a common practice with NIR instruments, and thus would allow a reduction in the number of samples needed for the calibration and avoid performing reference analysis in each factory.

Results from Kraggerud et al. (2014) plotted in Figure 2 revealed that MIR can predict free amino acids (FAA) better than NIR spectroscopy, whereas sensory traits and volatile compounds are predicted with similar accuracy by the 2 technologies. However, samples

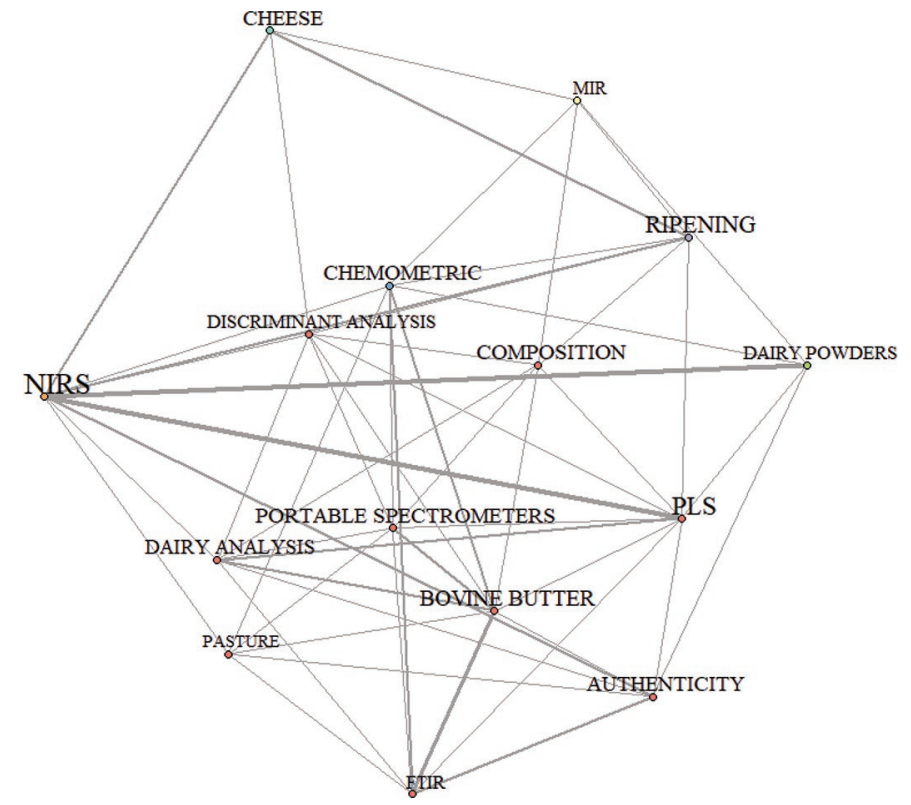

Figure 1. Authors' weighted key words network including the 15 more recurrent key words. NIRS = near-infrared spectroscopy; MIRS $=$ mid-infrared spectroscopy $;$ FTIR $=$ Fourier-transform infrared spectroscopy; PLS = partial least squares regression. Color version available online.

in Kraggerud et al. (2014) were differently prepared for each instrument (ground samples for MIR and intact for NIR) and thus the comparison between MIR and NIR spectroscopy in this case is not completely adequate. Margolies and Barbano (2018) also reported that MIR spectroscopy calibrated using 34 samples of

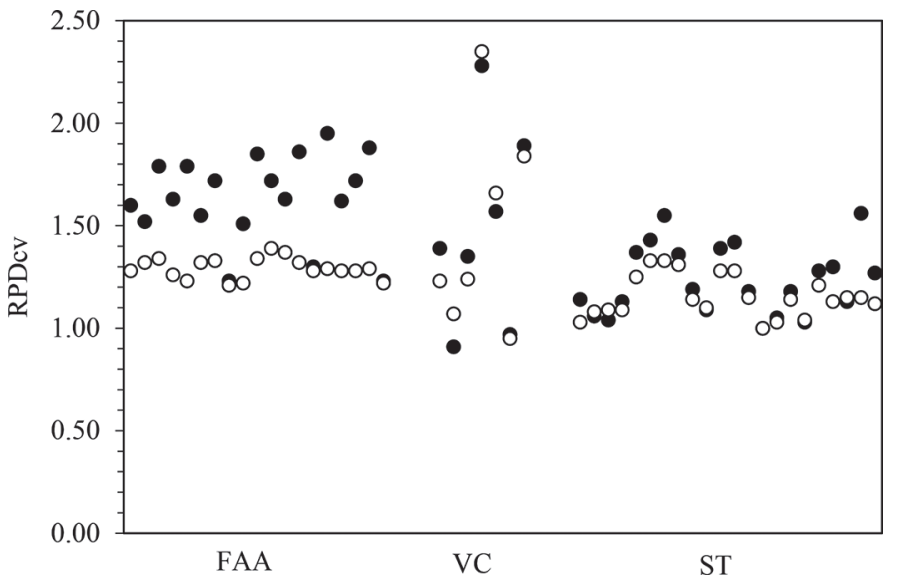

Figure 2. Ratio of prediction to deviation in cross-validation (RPDcv), calculated as SD/root mean square error in cross-validation, for free amino acids (FAA), volatile compounds (VC), and sensory traits (ST) in cheese using Fourier-transform mid-infrared spectroscopy in transmittance mode (black dots) and near-infrared spectroscopy in reflectance mode (white dots). Sensory traits were evaluated on a 9-point scale. Based on results of Kraggerud et al. (2014). 
Cheddar cheese from one dairy factory predicted more accurately the cheese composition in other 3 factories than NIR spectroscopy calibrated in each factory. On the other hand, total trans FA and natural occurring trans FA in butter were better predicted with NIR than MIR spectroscopy (Zhao et al., 2015). A similar probability of correct classification for Parmigiano Reggiano authentication has been reported for Fourier-transform NIR and MIR (Cevoli et al., 2013). Moreover, NIR spectroscopy instruments operating in transmittance or in reflectance mode performed similarly to predict mineral contents of soft cheese, with generally slightly greater coefficient of determination $\left(\mathrm{R}^{2}\right)$ in external validation than in cross-validation and using NIR in reflectance mode than in transmittance mode (Manuelian et al., 2017b). In the study of Manuelian et al. (2017b), the slight differences in terms of $\mathrm{R}^{2}$ in external validation between both NIR instruments could be due to the wider wavelength range covered by the reflectance instrument (866 to $2,530 \mathrm{~nm}$ ) than the transmittance instrument (850 to $1,050 \mathrm{~nm}$ ), revealing more peaks of absorbance.
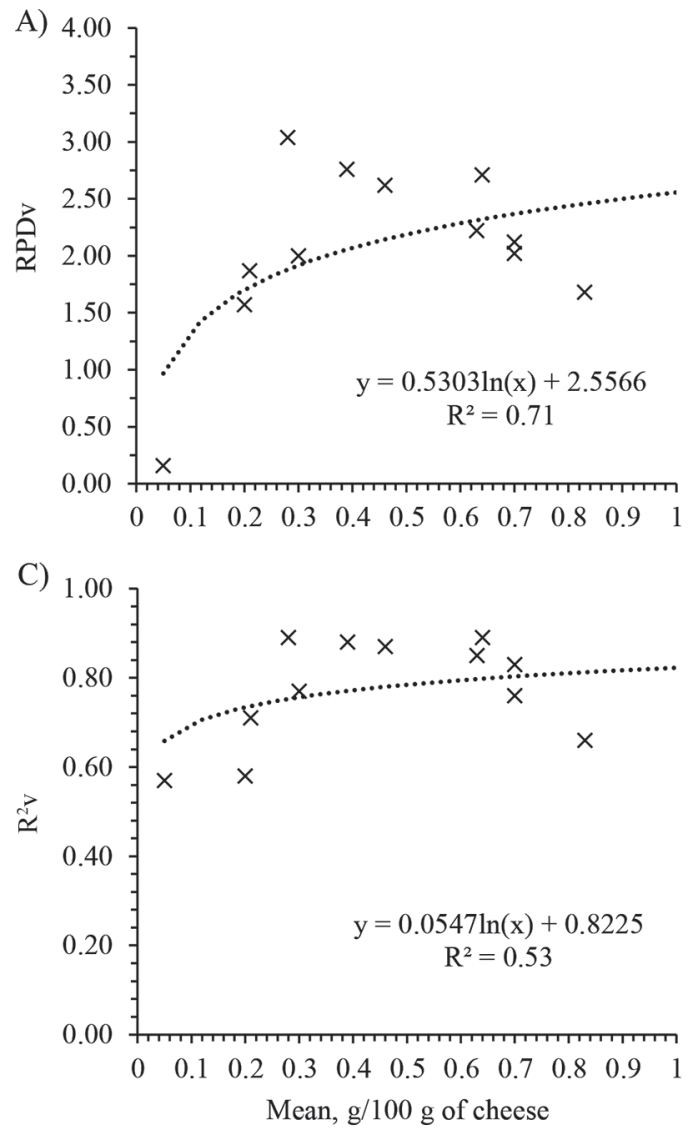

\section{CONCENTRATION, VARIABILITY, AND UNIT OF MEASUREMENT}

The concentration of a trait is a crucial point to develop prediction models (Soyeurt et al., 2006; Lucas et al., 2008) because absorbance depends on the quantity of molecular bonds; with a greater quantity, more molecular bonds can be excited. A large variability of reference data helps to build more accurate calibrations (Lucas et al., 2008; De Marchi et al., 2014). Thus, both concentration and variability should be considered when prediction equations are developed. The prediction to deviation (RPD), which is a nondimensional statistic, has been widely used for quick assessment of infrared calibrations (Williams, 2014). It is related to the error between the reference and the predicted values, and the standard deviation of the reference data. In general, high $\mathrm{R}^{2}$ results in high RPD. Following Williams (2014), RPD between 2.4 and 3 is adequate for a rough screening when analyzing difficult matrixes such as cheese. For example, the RPD of prediction models in external validation for $\mathrm{Ca}, \mathrm{Na}, \mathrm{P}, \mathrm{S}$, and $\mathrm{Mg}$ ranged
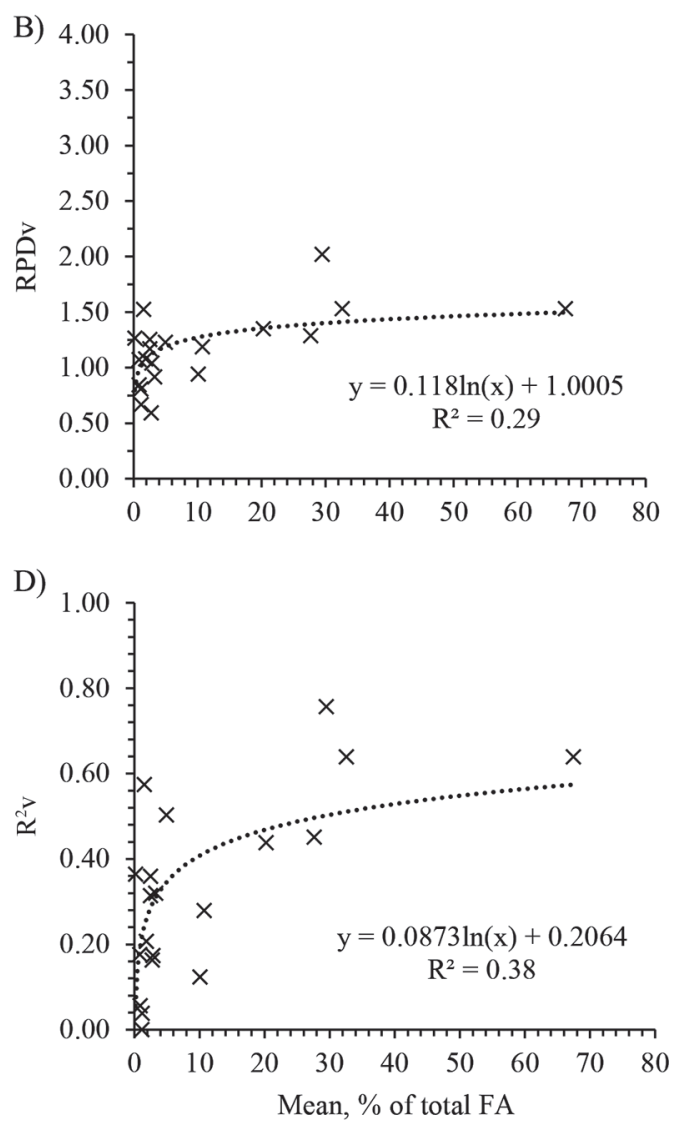

Figure 3. Relationship between total content of fatty acids (FA) expressed as grams per $100 \mathrm{~g}$ of cheese or \% of total FA and (A, B) the ratio of prediction to deviation in external validation (RPDv), calculated as SD/SE in prediction, and (C, D) the coefficient of determination in external validation $\left(\mathrm{R}^{2} \mathrm{v}\right)$ in cheese. Based on results of Manuelian et al. (2017a). 
from 2.35 to 3.73 and from 1.40 to 2.03 in Manuelian et al. (2017a) and Manuelian et al. (2017b), respectively; the difference can be attributed to the concentration of minerals and the variability of the reference data used to build the calibration equations. Indeed, the first study included 19 different varieties of soft, semi-hard, and hard cheeses, thus a greater concentration and variability of minerals, and the second study developed the calibration models on only one type of soft cheese. Minerals in milk are partially bond to the casein micelles (Gaucheron, 2005; Zamberlin et al., 2012), which explains the ability of infrared spectroscopy to predict minerals, even if they do not absorb in the infrared fragment (Buing-Pfaue, 2003).
Results for FA in cheese support that the accuracy of infrared predictions depends on concentration and unit of measurement, as it has been indicated previously for milk (Coppa et al., 2014; De Marchi et al., 2014). In general, greater RPD and $\mathrm{R}^{2}$ in external validation have been achieved for FA present in greater concentration, and when expressed as total amount rather than as relative concentration (Figure 3). This was also observed for protein fractions in milk, with the accuracy being poorer when expressed as a percentage of total proteins (McDermott et al., 2016, 2017; Niero et al., 2016). A strong logarithmic correlation (correlation coefficient, $\mathrm{r}=0.84$ ) has been observed between total amount of FA and RPD in external validation (Figure

Table 2. Prediction of quality traits in cheese using infrared spectroscopy

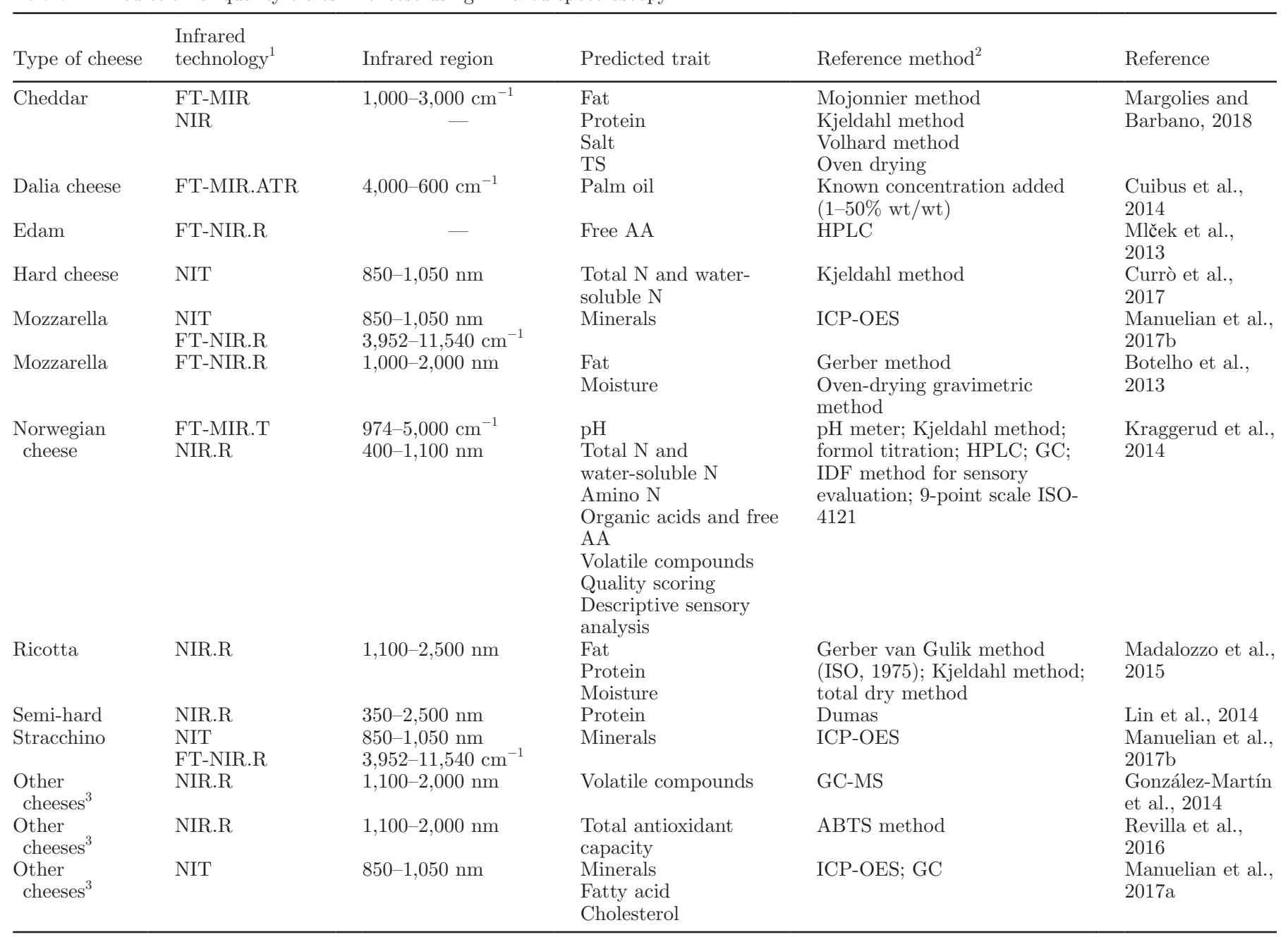

${ }^{1}$ FT-MIR = Fourier-transform mid-infrared spectroscopy; NIR = near-infrared spectroscopy; FT-NIR.R = Fourier-transform near-infrared spectroscopy in reflectance mode; FT-MIR.ATR = Fourier-transform mid-infrared spectroscopy with attenuated total reflectance; FT-MIR.T $=$ Fourier-transform mid-infrared spectroscopy in transmittance mode; NIR.R $=$ near-infrared spectroscopy in reflectance mode; NIT $=$ nearinfrared transmittance spectroscopy.

${ }^{2} \mathrm{ABTS}=2,2$-azino-bis(3-ethylbenzothiazoline-6-sulphonic acid); ICP-OES = inductively coupled plasma optical emission spectrometry; ISO = International Organization for Standardization; IDF = International Dairy Federation.

${ }^{3}$ Cow, ewe, and goat cheeses. 
3 ), similarly to the relationship reported by Soyeurt et al. (2006) in milk $(\mathrm{r}=0.86)$. The correlation decreased by $36 \%$ when considering the relative concentration instead of the total amount of the FA. Moreover, the correlation with total amount of FA was less strong when considering $\mathrm{R}^{2}$ in external validation $(\mathrm{r}=0.73)$. The differences in accuracy regarding unit of measurement for FA could be explained by the different distribution of the values of FA when expressed as a total amount or relative concentration, as can be observed in Figure
3. Moreover, FA prediction in cheese is based on the fingerprint obtained from scanning the sample, which means that the variation of fat percentage could affect it (De Marchi et al., 2014), whereas the reference values were obtained on the extracted fat fraction. However, starting from the same reference data, Coppa et al. (2014) reported that the reliability of the prediction models for FA in bulk milk was similar when models were developed on FA expressed as total amount or relative concentration.

Table 3. Fitting statistics ${ }^{1}$ of the prediction models for gross composition, total antioxidant capacity, palm oil, and cholesterol in cheese

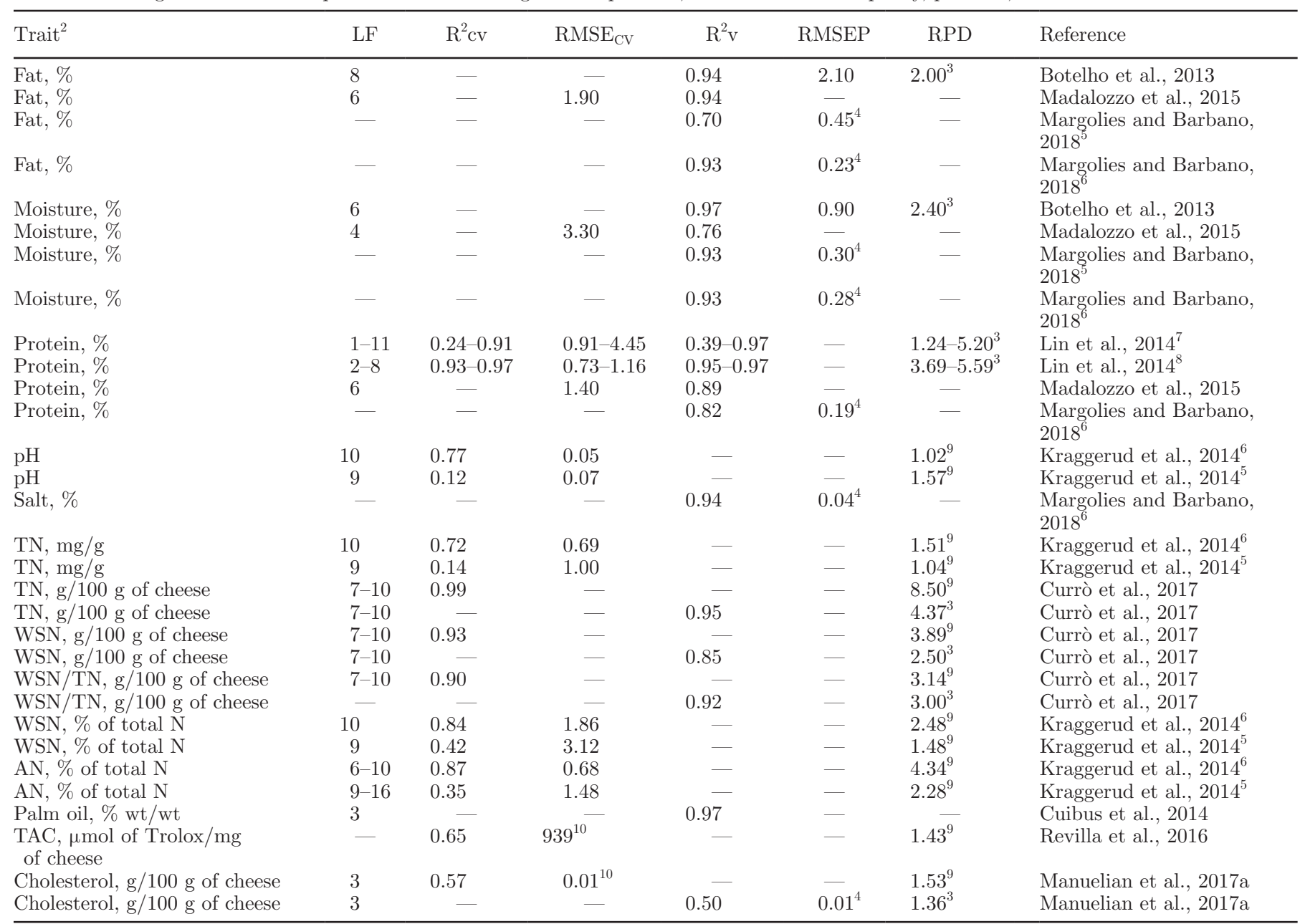

${ }^{1} \mathrm{LF}=$ latent factors; $\mathrm{R}^{2} \mathrm{cv}=$ coefficient of determination in cross-validation; $\mathrm{RMSE}_{\mathrm{CV}}=$ root mean square error in cross-validation; $\mathrm{R}^{2} \mathrm{v}=$ coefficient of determination in external validation; RMSEP = root mean square error of prediction; RPD = ratio of prediction to deviation calculated as $\mathrm{SD} / \mathrm{RMSE}_{\mathrm{CV}}$ or $\mathrm{SD} / \mathrm{RMSEP}$ or $\mathrm{SD} / \mathrm{SE}$ in cross-validation or external validation.

${ }^{2} \mathrm{TN}=$ total nitrogen; $\mathrm{WSN}=$ water-soluble nitrogen; $\mathrm{AN}=$ amino nitrogen; $\mathrm{TAC}=$ total antioxidant capacity.

${ }^{3}$ In external validation.

${ }^{4}$ Standard error in external validation.

${ }^{5}$ Near-infrared data.

${ }^{6}$ Fourier-transform mid-infrared data.

${ }^{7}$ Using partial least squares regression.

${ }^{8}$ Using kernel partial least squares regression.

${ }^{9}$ In cross-validation.

${ }^{10}$ Standard error in cross-validation. 
Therefore, the accuracy of the prediction models in dairy products strongly relies on the concentration of the investigated traits and on its variability, which can be increased including several types of cheese. The unit of measurement of the reference data could affect the reliability of the calibration model because it could modify both variability and concentration of the traits.

\section{PREDICTION OF SPECIFIC CHEMICAL COMPONENTS}

\section{Cheese}

Cheese is one of the most difficult dairy products to analyze using infrared spectroscopy because of the wide variability of cheese types and the heterogeneity of the product (Holroyd, 2013). Most of the published papers have developed prediction models based on only one type of cheese (Table 2), which resulted in a limited variability of the data set. Recently, González-Martín et al. (2014) and Revilla et al. (2016) included cheeses with different proportion of cow, ewe, and goat milk (from 0 to 100\%), and Manuelian et al. (2017a) sampled 19 different commercial cheeses produced using buffalo, cow, ewe, or goat milk to develop calibration models.
Most studies have built prediction models using wavelengths in the NIR region, and only 3 investigated the use of an instrument that worked in the MIR region. Studies that dealt with MIR spectroscopy scanned cheese samples after milling (Cuibus et al., 2014; Kraggerud et al., 2014) or in a particle-free dispersion (Margolies and Barbano, 2018). On the other hand, studies that used NIR spectroscopy usually recorded absorbance in reflectance mode, with no pre-treatment of the sample. Although previous studies indicated that the milling process improved the predictive ability of NIR spectroscopy in food because of the homogenization of the sample, calibrations developed with intact samples (without any sample preparation) are fundamental for the on-line implementation in the dairy industry.

In the last years, few papers have dealt with traditional measures of gross composition, usually in intact samples, and most studies investigated the determination of less common traits that are more difficult to predict with infrared technologies because they are not related to specific absorptions bands (e.g., minerals and sensory analysis) or are present in very low concentrations (e.g., cholesterol and volatile compounds). It has been reported that the limit of sensitivity of infrared

Table 4. Fitting statistics ${ }^{1}$ of the prediction models for free amino acids (FAA) in cheese

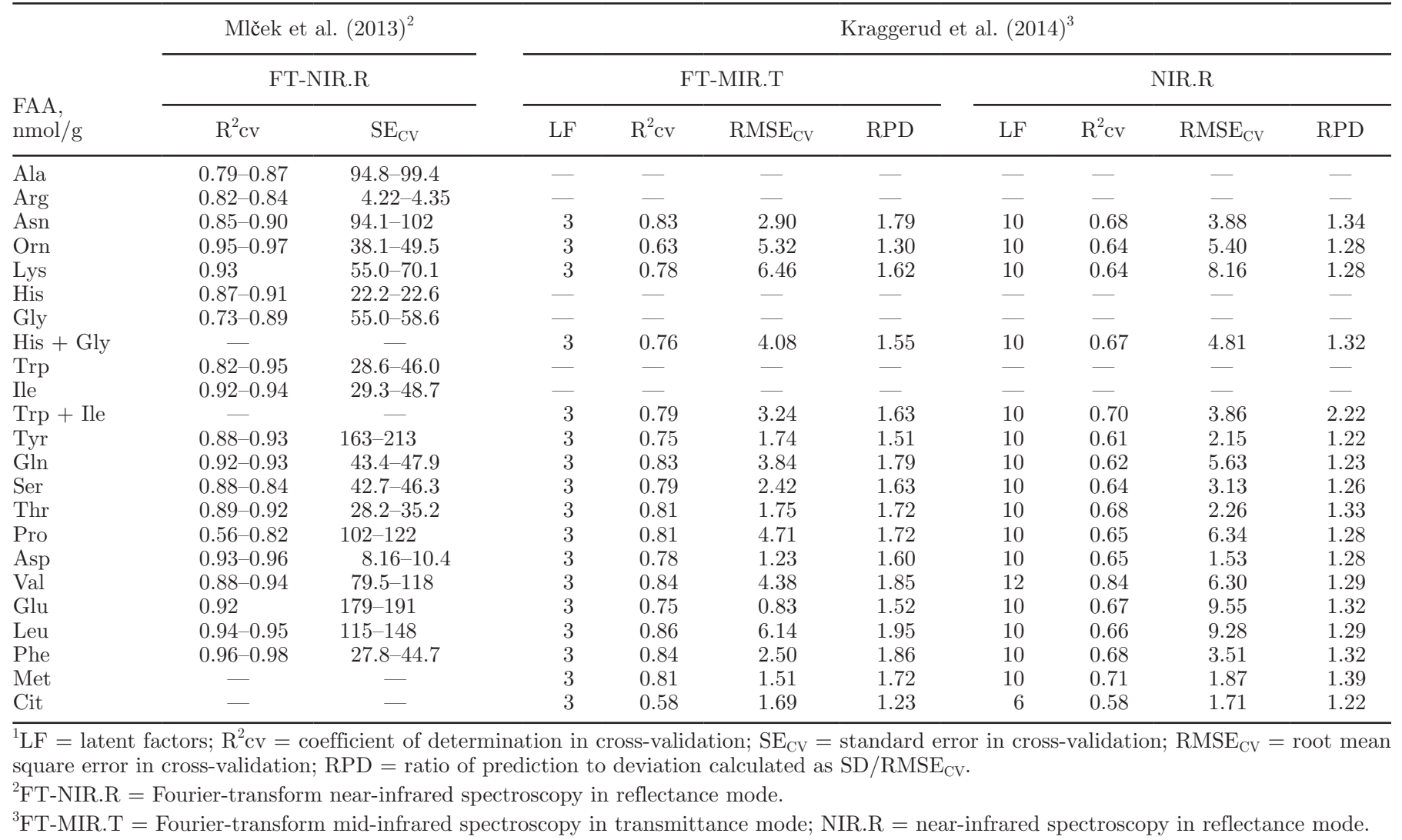


spectroscopy for most constituents is $0.1 \%$ (Iwamoto et al., 1995).

Almost all prediction models have been built using partial least squares (PLS) regression. Only 4 studies used modified PLS (MPLS) regression (GonzálezMartín et al., 2014; Revilla et al., 2016; Currò et al., 2017; Manuelian et al., 2017a), and one used kernel PLS regression (Lin et al., 2014). The MPLS approach is considered more accurate and stable than the PLS approach (González-Martín et al., 2014) because the algorithm for MPLS considers the standardized residuals after each factor before moving to the next factor (Meagher et al., 2007). The PLS regression is based on a linear relationship between the predictor and the response, and thus a data set with strong nonlinear characteristics between the predictor and the response results in poor performance of the PLS (Rosipal and Trejo, 2002). The kernel PLS is a natural extension of PLS to deal with nonlinear data (Rosipal and Trejo, 2002), and it is considered a better procedure to extract principal components and obtain more information than the PLS (Bai et al., 2006).

Fitting Statistics for Gross Composition, Total Antioxidant Capacity, Palm Oil, and Cholesterol. Fitting statistics reported in the literature for cheese gross composition, total antioxidant capacity, palm oil, and cholesterol content are summarized in Table 3. The number of samples used to develop and validate the prediction models ranged from 11 to 459 . Models were validated through cross-validation or external validation, independently. When the 2 validation procedures were tested in the same data set (Currò et al., 2017), better fitting statistics were obtained with the cross-validation approach. For protein content, better fitting statistics were obtained using kernel PLS than standard PLS regression (Lin et al., 2014). Only few prediction models achieved an RPD between 2.4 and 3, and with the exception of Lin et al. (2014), all of them on ground samples. However, even if the RPD in cross-validation for total antioxidant capacity was lower than 1.5, the reference and the NIR values from an external data set of 64 samples showed no statistical differences ( $P=0.48$; Revilla et al., 2016). As indicated before, prediction models of the same trait could perform differently depending on the sample preparation, the infrared instruments, and the wavelength region used (Kraggerud et al., 2014; Margolies and Barbano, 2018).

Fitting Statistics for FAA, Volatile Compounds, Organic Acids, Sensory Traits, Minerals, and $\boldsymbol{F A}$. The amount and type of FAA in cheese depend mainly on the type of cheese and ripening time.

Table 5. Fitting statistics ${ }^{1}$ of the prediction models for volatile compounds and organic acids in cheese using near-infrared spectroscopy in reflectance mode (NIR.R) or Fourier-transform mid-infrared spectroscopy in transmittance mode (FT-MIR.T)

\begin{tabular}{|c|c|c|c|c|c|c|c|c|c|c|c|}
\hline \multirow[b]{3}{*}{ Item } & \multicolumn{3}{|c|}{$\begin{array}{c}\text { González-Martín et al. } \\
\qquad(2014)\end{array}$} & \multicolumn{8}{|c|}{ Kraggerud et al. (2014) } \\
\hline & \multicolumn{3}{|c|}{ NIR.R } & \multicolumn{4}{|c|}{ FT-MIR.T } & \multicolumn{4}{|c|}{ NIR.R } \\
\hline & $\mathrm{LF}$ & $\mathrm{SE}_{\mathrm{CV}}$ & $\mathrm{RPD}$ & LF & $\mathrm{R}^{2} \mathrm{cv}$ & $\mathrm{RMSE}_{\mathrm{CV}}$ & $\mathrm{RPD}$ & LF & $\mathrm{R}^{2} \mathrm{cv}$ & $\mathrm{RMSE}_{\mathrm{CV}}$ & $\mathrm{RPD}$ \\
\hline \multicolumn{12}{|l|}{ Volatile compound, \% } \\
\hline Acetaldehyde & 8 & 0.06 & 2.30 & 10 & 0.53 & 0.37 & 1.39 & 9 & 0.28 & 0.42 & 1.23 \\
\hline i-Propanol & - & - & - & 10 & 0.50 & 0.88 & 1.35 & 9 & 0.33 & 0.96 & 1.24 \\
\hline n-Propanol & - & - & - & 10 & 0.58 & 0.27 & 2.28 & 9 & 0.60 & 0.26 & 2.35 \\
\hline 2-Butanol & 6 & 1.93 & 2.10 & 10 & 0.38 & 2.52 & 1.89 & 9 & 0.26 & 2.6 & 1.84 \\
\hline 2-Pentanol & 8 & 0.32 & 1.80 & - & - & - & - & - & - & - & - \\
\hline 3-Methyl-1-butanol & 8 & 0.07 & 1.70 & - & - & - & - & - & - & - & - \\
\hline 2-Butanone & 6 & 0.38 & 1.70 & 10 & 0.29 & 0.92 & 1.57 & 9 & 0.38 & 0.87 & 1.66 \\
\hline 2-Pentanone & 8 & 0.59 & 2.00 & - & - & - & - & - & - & - & - \\
\hline Acetoin, $\mathrm{mmol} / \mathrm{kg}$ & - & - & - & 10 & 0.61 & 0.11 & 1.11 & 9 & 0.67 & 0.10 & 1.19 \\
\hline Acetic acid, $\mathrm{mmol} / \mathrm{kg}$ & - & - & - & 10 & 0.63 & 0.65 & 1.20 & 9 & 0.59 & 0.68 & 1.15 \\
\hline Butyric acid, $\mathrm{mmol} / \mathrm{kg}$ & - & - & - & 10 & 0.51 & 0.09 & 1.42 & 9 & 0.35 & 0.10 & 1.31 \\
\hline Pyruvate, $\mathrm{g} / \mathrm{kg}$ & - & - & - & 10 & 0.38 & 0.02 & 1.94 & 9 & 0.32 & 0.02 & 1.92 \\
\hline Succinic acid, $\mathrm{g} / \mathrm{kg}$ & - & - & - & 10 & 0.53 & 0.14 & 1.26 & 9 & 0.48 & 0.14 & 1.22 \\
\hline Lactic acid, $\mathrm{g} / \mathrm{kg}$ & - & - & - & 10 & 0.74 & 0.61 & 1.63 & 9 & 0.49 & 0.78 & 1.27 \\
\hline
\end{tabular}

${ }^{1} \mathrm{LF}=$ latent factors; $\mathrm{SE}_{\mathrm{CV}}=$ standard error in cross-validation; $\mathrm{RPD}=$ ratio of prediction to deviation calculated as $\mathrm{SD} / \mathrm{SE} \mathrm{CV}_{\mathrm{C}}$ or $\mathrm{SD} / \mathrm{RMSE} \mathrm{CV}_{\mathrm{C}}$; $\mathrm{R}^{2} \mathrm{cv}=$ coefficient of determination in cross-validation; $\mathrm{RMSE}_{\mathrm{CV}}=$ root mean square error in cross-validation. 
Free AA are partially responsible for the taste of the product and can be used as markers to monitor cheese ripening (Mlček et al., 2013; Kraggerud et al., 2014). As reported in Table 4, the coefficient of determination in cross-validation $\left(\mathbf{R}^{2} \mathbf{c v}\right)$ for FAA ranged from 0.56 to 0.96. The study of Mlček et al. (2013) was conducted on intact samples of Edam cheese using Fourier-transform NIR spectroscopy in reflectance mode and prediction models for the majority of FAA had $\mathrm{R}^{2} \mathrm{cv}$ between 0.85 and 0.95 . Kraggerud et al. (2014) reported $R^{2} \mathrm{cv}$ lower than 0.70 for prediction models of most FAA determined on intact samples of Norwegian cheese using NIR spectroscopy in reflectance mode. Moreover, Fourier-transform MIR spectroscopy in transmittance mode performed generally better $\left(\mathrm{R}^{2} \mathrm{cv}\right.$ between 0.75 and 0.85 ) than NIR spectroscopy in reflectance mode for several FAA (Kraggerud et al., 2014). However, as indicated above, a direct comparison between transmittance and reflectance modes in the study of Kraggerud et al. (2014) is not possible because both instruments worked in a different infrared range (MIR and NIR regions), and samples were presented differently in each instrument (ground samples for MIR and intact for NIR analysis). The accuracy of the predicted models reported in Table 4 for FAA in cheese was similar to the prediction models of FFA in milk (McDermott et al., 2016). Volatile compounds have shown RPD of the prediction models between 0.91 and 3.40 , with several latent factors between 6 and 10 (Table 5). GonzálezMartín et al. (2014) reported better results than Kraggerud et al. (2014) probably due to greater variability of the cheeses included in the study: Kraggerud et al. (2014) studied only Norwegian cheese, whereas González-Martín et al. (2014) included cheese made from cow, ewe, and doe milk in different proportions. Only one study (Kraggerud et al., 2014) in the recent literature developed prediction models for several organic acids; however, as observed in Table 5, the accuracy of the models was low. The low accuracy for the FAA, volatile compounds, and organic acids could partially be related to the reference laboratory analysis because when more steps are involved, the error of laboratory increases and this will directly affect the accuracy of the prediction models (De Marchi et al., 2014). Kraggerud et al. (2014) also attempted to predict sensory traits using Fourier-transform MIR spectroscopy in transmittance mode or NIR spectroscopy in reflectance mode (Table 6), but with unsatisfactory

Table 6. Fitting statistics ${ }^{1}$ of the prediction models for quality and sensory traits in cheese using Fourier-transform mid-infrared spectroscopy in transmittance mode (FT-MIR.T) or near-infrared spectroscopy in reflectance mode (NIR.R; Kraggerud et al., 2014)

\begin{tabular}{|c|c|c|c|c|c|c|c|c|}
\hline \multirow[b]{2}{*}{ Item } & \multicolumn{4}{|c|}{ FT-MIR.T } & \multicolumn{4}{|c|}{ NIR.R } \\
\hline & $\mathrm{LF}$ & $\mathrm{R}^{2} \mathrm{cv}$ & $\mathrm{RMSE}_{\mathrm{CV}}$ & $\mathrm{RPD}$ & $\mathrm{LF}$ & $\mathrm{R}^{2} \mathrm{cv}$ & $\mathrm{RMSE}_{\mathrm{CV}}$ & $\mathrm{RPD}$ \\
\hline Overall & 5 & 0.44 & 0.36 & 1.11 & 15 & 0.36 & 0.37 & 1.07 \\
\hline Appearance & 5 & 0.13 & 0.44 & 1.01 & 15 & 0.36 & 0.42 & 1.07 \\
\hline Consistency & 5 & 0.61 & 0.29 & 1.03 & 15 & 0.47 & 0.32 & 1.14 \\
\hline Flavor & 5 & 0.51 & 0.36 & 1.16 & 15 & 0.44 & 0.38 & 1.11 \\
\hline Shear firmness & 5 & 0.29 & 0.39 & 1.06 & 15 & 0.38 & 0.38 & 1.08 \\
\hline Odor intensity & 5 & 0.27 & 0.37 & 1.04 & 15 & 0.20 & 0.36 & 1.09 \\
\hline Elasticity & 5 & 0.49 & 0.46 & 1.13 & 15 & 0.42 & 0.47 & 1.09 \\
\hline Cohesion & 5 & 0.69 & 0.48 & 1.37 & 15 & 0.60 & 0.53 & 1.25 \\
\hline Firmness chewing & 5 & 0.77 & 0.46 & 1.56 & 15 & 0.67 & 0.54 & 1.33 \\
\hline Pasty & 5 & 0.76 & 0.46 & 1.55 & 15 & 0.67 & 0.98 & 1.33 \\
\hline Solubility & 5 & 0.68 & 0.51 & 1.36 & 15 & 0.65 & 0.53 & 1.31 \\
\hline Malty & 5 & 0.22 & 0.26 & 1.00 & 15 & 0.22 & 0.26 & 1.00 \\
\hline Sweetness & 5 & 0.09 & 0.25 & 1.05 & 15 & 0.12 & 0.26 & 1.03 \\
\hline Acidic & 5 & 0.53 & 0.36 & 1.18 & 15 & 0.48 & 0.38 & 1.14 \\
\hline Salty & 5 & 0.24 & 0.21 & 1.03 & 15 & 0.28 & 0.21 & 1.04 \\
\hline Pungent & 5 & 0.61 & 0.43 & 1.28 & 15 & 0.53 & 0.46 & 1.21 \\
\hline Bitter & 5 & 0.62 & 0.42 & 1.30 & 15 & 0.44 & 0.48 & 1.13 \\
\hline Sulfurous & 5 & 0.47 & 0.64 & 1.13 & 15 & 0.50 & 0.63 & 1.15 \\
\hline
\end{tabular}

${ }^{1} \mathrm{LF}=$ latent factors; $\mathrm{R}^{2} \mathrm{cv}=$ coefficient of determination in cross-validation; $\mathrm{RMSE} \mathrm{E}_{\mathrm{CV}}=$ root mean square error in cross-validation; $\mathrm{RPD}=$ ratio of prediction to deviation calculated as $\mathrm{SD} / \mathrm{RMSE}_{\mathrm{CV}}$. 
results, which was expected because sensory attributes are not directly linked to an absorption infrared region or to organic molecules, and the reference values are based on a subjective evaluation. Minerals in cheese were successfully predicted using infrared technology when considering a wide variety of cheeses (Manuelian et al., 2017a), achieving an RPD greater than 3 for $\mathrm{Ca}$, $\mathrm{P}, \mathrm{S}, \mathrm{Mg}, \mathrm{Zn}$, and $\mathrm{Cu}$ (Table 7), probably because part of minerals in cheese are linked to organic complexes that can be detected through infrared spectroscopy, as mentioned above. Prediction models for Mozzarella and Stracchino cheeses were probably poor due to the lower mineral content and lower variability (Manuelian et al., 2017b). Fatty acids in cheese were better predicted considering the total amount instead of the relative concentration (Table 8) with an RPD greater than 2.5 for SFA, UFA, MUFA, and PUFA, almost all major FA, and some minor FA. In addition, more abundant FA were more accurately predicted.

\section{Butter, Milk Powder, and Yogurt}

To our knowledge, only few studies have focused on dairy products other than cheese (Table 9). Butter and butterfat were the object of investigation of most papers, and almost all used Fourier-transform MIR spectroscopy with attenuated total reflectance instruments and scanned the sample without preparation due to the physical characteristics of the product. The number of samples for butter ranged from 26 to 60 , and prediction models were built using PLS regression and validated with external validation procedure, except for one study that used cross-validation (Nurrulhidayah et al., 2013). Studies on butter and butterfat products dealt with the prediction of specific FA of interest for human nutrition. Good accuracy $\left(\mathrm{R}^{2}\right.$ in external validation between 0.77 and 0.98 ) was obtained for total trans FA, natural occurring trans FA, CLA, and palm oil (Table 10). Prediction equations for milk powder

Table 7. Fitting statistics ${ }^{1}$ of the prediction models for minerals using near-infrared transmittance (NIT) spectroscopy and Fourier-transform near-infrared spectroscopy in reflectance mode (FT-NIR.R) in Mozzarella and Stracchino cheeses (Manuelian et al., 2017b), and other cheeses ${ }^{2}$ (Manuelian et al., 2017a)

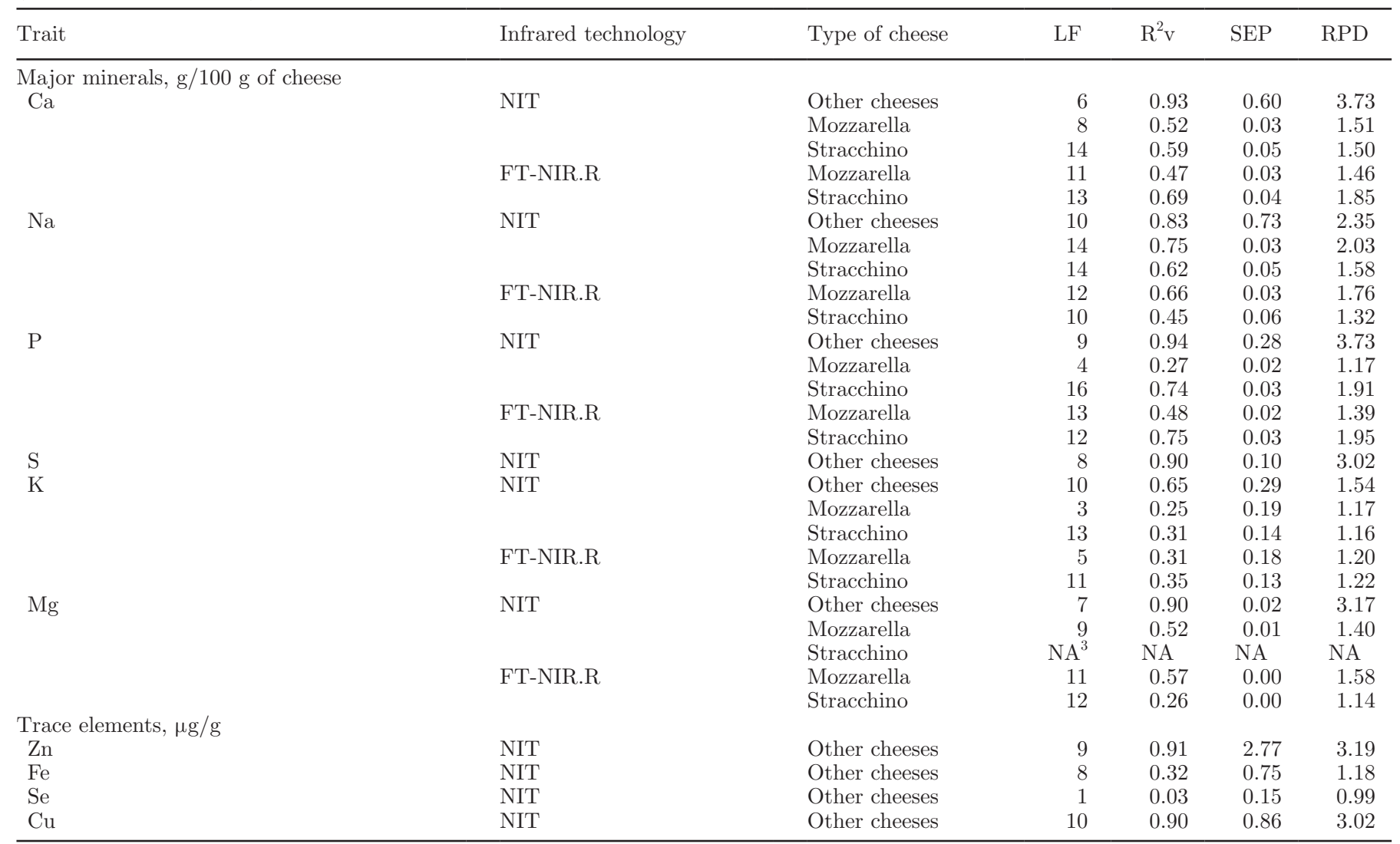

${ }^{1} \mathrm{LF}=$ latent factors; $\mathrm{R}^{2} \mathrm{v}=$ coefficient of determination in external validation; $\mathrm{SEP}=$ standard error of prediction; $\mathrm{RPD}=$ ratio of prediction to deviation calculated as SD/SEP.

${ }^{2}$ Cow, ewe, and goat cheeses.

${ }^{3} \mathrm{NA}=$ not achieved. 
were also developed using PLS regression and validated with external (Capuano et al., 2015) or cross-validation procedures (Chitra et al., 2016). Good accuracy was reported for milk powder with regard to the predicted traits listed in Table 11. Only one study has focused on yogurt (Grassi et al., 2013) using Fourier-transform NIR spectroscopy in transflectance mode to monitor the lactic acid fermentation, showing that the prediction equations were similar to those developed for rheological data. The 2 models provided the same times for the critical points of the fermentation process.

\section{APPLICATION FOR AUTHENTICITYIADULTERATION AND DISCRIMINANT ANALYSIS IN DAIRY PRODUCTS}

Methods to certificate authenticity of the products are important both for human health and fraud detection. Consumers from Western countries are willing to pay a higher price for products considered of high quality because they come, for example, from organic farms, slow-food production, and protected designation of origin. Most methods used to guarantee the quality standard requirements (e.g., raw materials origin and purity) are expensive and time-consuming. Once again, infrared technologies offer a fast analysis of the products detecting or quantifying a specific component
(Nurrulhidayah et al., 2013; Capuano et al., 2015; Cuibus et al., 2015; Plans Pujolras et al., 2015; Lim et al., 2016). When quantification or detection of a specific component is not possible, infrared technologies still offer the possibility to discriminate samples by identifying peculiar spectral differences using supervised methods such as artificial neural networks and discriminant analysis or unsupervised methods such as hierarchical clustering, showing that infrared spectra are able to discriminate between brands, feeding regimen, storage temperature, and ripening time, detection of adulterants in the product, and regions of origin (Table 12).

As previously discussed, absorbance depends on the vibrations of the molecule bonds and because of this, it is important to establish the limit of detection or quantification to evaluate the usefulness of infrared technologies to detect fraud for the specific trait in the tested matrix. For example, references reported in Table 13 fixed a limit of detection around $0.2 \%$ for CLA and trans FA, and between 1.5 and 3\% to detect adulteration with palm oil, acid whey, starch, maltodextrin, and gelatin. As expected, the limit for quantification of those components was greater than the limit for detection. To correctly classify samples in clusters, groups should be clearly separated. For example, to achieve a $100 \%$ correct classification of organic and conventional butter, Plans Pujolras et al. (2015) indicated an inter-

Table 8. Fitting statistics ${ }^{1}$ of the prediction models for fatty acids (FA) in cheese expressed as total content of FA (Manuelian et al., 2017a) and as relative amount of total FA (data not shown in Manuelian et al., 2017a)

\begin{tabular}{|c|c|c|c|c|c|c|c|c|}
\hline \multirow[b]{2}{*}{ Trait } & \multicolumn{4}{|c|}{$\mathrm{g} / 100 \mathrm{~g}$ of cheese } & \multicolumn{4}{|c|}{$\%$ of total FA } \\
\hline & $\mathrm{LF}$ & $\mathrm{R}^{2} \mathrm{v}$ & SEP & $\mathrm{RPD}$ & $\mathrm{LF}$ & $\mathrm{R}^{2} \mathrm{v}$ & SEP & $\mathrm{RPD}$ \\
\hline \multicolumn{9}{|l|}{ FA group } \\
\hline SFA & 9 & 0.97 & 0.89 & 4.73 & 10 & 0.64 & 0.92 & 1.53 \\
\hline UFA & 8 & 0.92 & 0.53 & 3.58 & 10 & 0.64 & 0.92 & 1.53 \\
\hline MUFA & 10 & 0.92 & 0.47 & 3.50 & 10 & 0.45 & 0.79 & 1.29 \\
\hline PUFA & 8 & 0.87 & 0.15 & 2.74 & 10 & 0.50 & 0.53 & 1.23 \\
\hline CLA & 7 & 0.58 & 0.04 & 1.57 & 9 & 0.18 & 0.23 & 1.07 \\
\hline $\mathrm{n}-3$ & 8 & 0.71 & 0.04 & 1.87 & 10 & 0.06 & 0.18 & 0.85 \\
\hline $\mathrm{n}-6$ & 9 & 0.76 & 0.11 & 2.02 & 8 & 0.17 & 0.47 & 1.04 \\
\hline \multicolumn{9}{|l|}{ Major FA } \\
\hline C14:0 & 7 & 0.91 & 0.19 & 3.25 & 10 & 0.28 & 0.47 & 1.19 \\
\hline C16:0 & 10 & 0.90 & 0.50 & 3.17 & 9 & 0.76 & 1.21 & 2.02 \\
\hline C18:0 & 9 & 0.82 & 0.24 & 2.30 & 8 & 0.12 & 0.67 & 0.94 \\
\hline C18:1n-9 & 10 & 0.91 & 0.32 & 3.38 & 9 & 0.44 & 0.71 & 1.35 \\
\hline \multicolumn{9}{|l|}{ Minor FA } \\
\hline $\mathrm{C} 4: 0$ & 6 & 0.89 & 0.06 & 2.71 & 3 & 0.36 & 0.16 & 1.25 \\
\hline C6:0 & 7 & 0.87 & 0.04 & 2.62 & 10 & 0.21 & 0.13 & 1.08 \\
\hline C8:0 & 5 & 0.77 & 0.03 & 2.00 & 10 & 0.04 & 0.11 & 0.67 \\
\hline C10:0 & 7 & 0.83 & 0.08 & 2.12 & 10 & 0.16 & 0.31 & 0.59 \\
\hline C12:0 & 10 & 0.66 & 0.11 & 1.68 & 9 & 0.32 & 0.34 & 0.92 \\
\hline C15:0 & 8 & 0.89 & 0.02 & 3.04 & 10 & 0.00 & 0.07 & 0.81 \\
\hline C16:1 & 9 & 0.88 & 0.03 & 2.76 & 10 & 0.57 & 0.13 & 1.52 \\
\hline C18:2n-6 & 9 & 0.85 & 0.09 & 2.22 & 10 & 0.31 & 0.43 & 1.17 \\
\hline $\mathrm{C} 20: 0$ & 8 & 0.57 & 0.07 & 0.16 & 9 & 0.36 & 0.03 & 1.27 \\
\hline
\end{tabular}

${ }^{1} \mathrm{LF}=$ latent factors; $\mathrm{R}^{2} \mathrm{v}=$ coefficient of determination in external validation; $\mathrm{SEP}=$ standard error of prediction; $\mathrm{RPD}=$ ratio of prediction to deviation calculated as $\mathrm{SD} / \mathrm{SEP}$. 


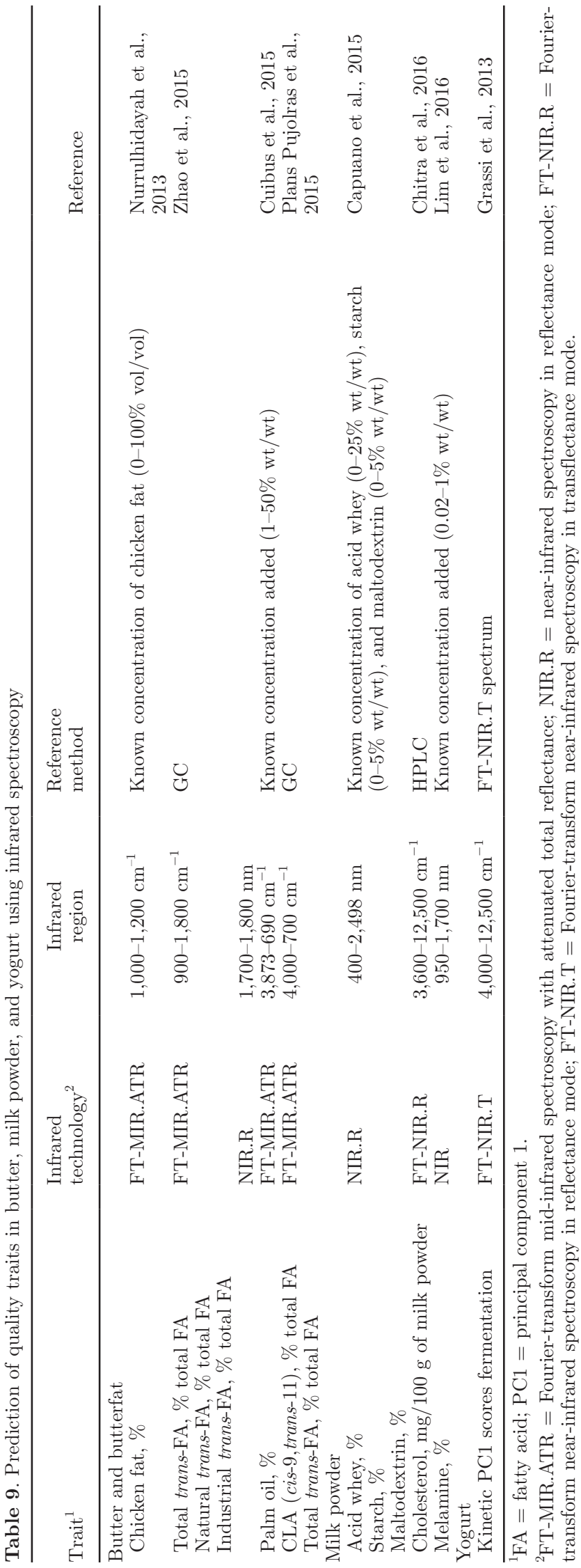

class difference of 1.8. Good classification has been also obtained for ripening index, storage temperature, storage week, and cow feeding (Table 12). In some cases, differences between spectra can be due to a specific wavenumber, wavelength or a range, which facilitate the quantification of that compound. For example, Nurrulhidayah et al. (2013) reported that butter and chicken fat peak intensities differed at frequency 1,200 to $1,000 \mathrm{~cm}^{-1}$. Plans Pujolras et al. (2015) observed that the most important wavenumber associated to separate organic from conventional butter was $967 \mathrm{~cm}^{-1}$, which is related to trans-fat absorption bands. Capuano et al. (2015) observed that the wavelengths 1,950, 1,980, $2,040,1,650$ to 1,720 , and 2,250 to $2,315 \mathrm{~nm}$ were important for the prediction of the percentage of added acid whey in milk powder. For starch adulteration the relevant peaks were 1,410,1,910, 1,950, 2,180, 2,260, and 2,280 nm; and for maltodextrin 1,440, 1,915, 2,040, and 2,420 nm (Capuano et al., 2015).

Moreover, MIR spectra have shown their ability to detect molecular changes in cheese (Loudiyi and AitKaddour, 2018) and milk powder (Ye et al., 2017) such as rearrangements of protein matrix, fat globules structure, conformational disorder of lipid acyl chain, and modification of the protein-protein interaction. For example, in Cantal cheese it was described as a broadening of the 2,923 and $2,853 \mathrm{~cm}^{-1}$ band proportional to the level of $\mathrm{NaCl}$ substitution by $\mathrm{KCl}$, and an increase of the intensity of the water and proteins associated bands when temperature increased from 20 to $60^{\circ} \mathrm{C}$ (Loudiyi and Ait-Kaddour, 2018). In milk powder, changes were mainly observed in absorbance bands of 1,540, 1,650, 1,740 , and $1,750 \mathrm{~cm}^{-1}$.

\section{CONCLUSIONS}

This review showed the importance of having samples with high variability to account for a wider range of concentration of the traits to be studied. Thus, involving several cheese types from different dairy species and managerial conditions could help increasing the variability and thus the reliability of the prediction models. Prediction accuracy could also depend on the unit of measurement of reference values, and on differences between the sample presentation for the reference analysis and the infrared spectroscopy. For example, to determine FA, the laboratory analysis is performed on the extracted fat fraction, whereas the spectrum is collected on the complete cheese sample.

Few studies have attempted to develop prediction models for minor chemical attributes such as FAA, volatile compounds, organic acids, sensory traits, and minerals, and it is difficult to compare the results because the studies were conducted following different 
Table 10. Fitting statistics ${ }^{1}$ of the prediction models for total trans-fatty acids (FA), naturally occurring trans-FA, industrially occurring transFA, CLA, and palm oil in butter and butterfat

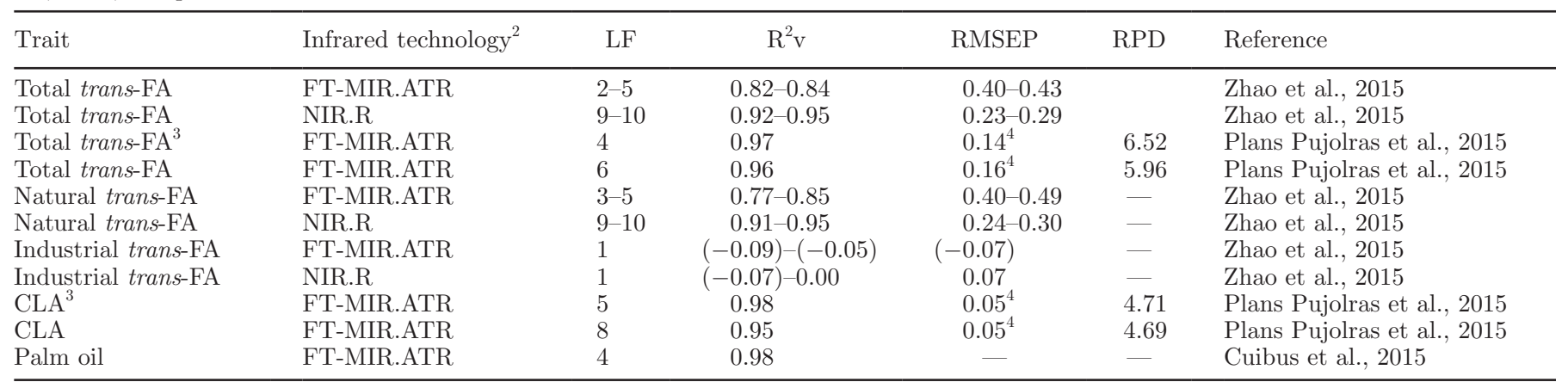

${ }^{1} \mathrm{LF}=$ latent factors; $\mathrm{R}^{2} \mathrm{v}=$ coefficient of determination in external validation; $\mathrm{RMSEP}=$ root mean square error of prediction; $\mathrm{RPD}=$ ratio of prediction to deviation calculated as $\mathrm{SD} / \mathrm{SE}$ of prediction.

${ }^{2}$ FT-MIR.ATR $=$ Fourier-transform mid-infrared spectroscopy with attenuated total reflectance; NIR.R $=$ near-infrared spectroscopy in reflectance mode.

${ }^{3}$ Trait analyzed in butterfat.

${ }^{4}$ Standard error of prediction.

sampling preparations (i.e., ground, liquid, and intact) and using different infrared regions (MIR and NIR) and modes (reflectance and transmittance). Moreover, these chemical components and attributes were difficult to predict because they are not linked to an absorption band in the infrared region, and their detection is based on the variation that they produce on the absorption band of other components. However, infrared technology has demonstrated its potential for process control, sample discrimination, and prediction of quality traits (e.g., minerals, FA, and FAA) and indices (e.g., ripening time) during food processing and final products at small-scale and laboratory-controlled environments.

\section{PERSPECTIVES}

Further research is needed to evaluate the effect of implementing infrared technology at industry scale for routine on-line monitoring of the quality of dairy products in an effort to ensure appropriate scaling up and increase the robustness of the prediction models. The broad implementation of infrared technologies at the industry level depends on several factors such as the improvement of equipment designs (e.g., dimensions, robustness, easy-to-use), the reduction of the costs to acquire the devices and to maintain accuracy of the calibrations, and the increase of processing speed. Moreover, to enhance the accuracy of prediction models for some quality traits it could be interesting to combine the acquisition of spectral and spatial information through the use of hyperspectral imaging.

Strong effort is needed to deepen the effect of the wavelength range (MIR and NIR) and the mode (reflectance, transmittance, and transflectance) on the outcome of prediction models. The few studies that dealt with comparisons among different infrared technologies to predict quality of dairy products reported differences in the accuracy of the prediction models and in the cost of developing and maintaining the prediction models that were not trivial. This point is crucial especially when new traits are predicted, and thus future research is needed to help the dairy industry to select the most

Table 11. Fitting statistics ${ }^{1}$ of the prediction models for acid whey, starch, maltodextrin, cholesterol, melamine, and protein in milk powder

\begin{tabular}{llclll}
\hline Trait & Infrared technology $^{2}$ & LF & $\mathrm{R}^{2} \mathrm{v}$ & RMSEP & Reference \\
\hline Acid whey & NIR.R & 11 & 0.98 & 1.50 & Capuano et al., 2015 \\
Starch & NIR.R & 9 & 0.98 & 0.36 & Capuano et al., 2015 \\
Maltodextrin & NIR.R & 6 & 0.90 & 0.64 & Capuano et al., 2015 \\
Cholesterol & FT-MIR.ATR & $7-10$ & $0.98-0.99^{3}$ & $1.05-7.54^{4}$ & Chitra et al., 2016 \\
Melamine & NIR & 8 & 0.96 & 0.07 & Lim et al., 2016 \\
Protein & FT-NIR.R & $5-8$ & $0.97-0.99$ & $0.37-0.59$ & Chen et al., 2018 \\
\hline
\end{tabular}

${ }^{1} \mathrm{LF}=$ latent factors; $\mathrm{R}^{2} \mathrm{v}=$ coefficient of determination in external validation; RMSEP = root mean square error of prediction.

${ }^{2}$ FT-MIR.ATR = Fourier-transform mid-infrared spectroscopy with attenuated total reflectance; NIR = near-infrared spectroscopy; NIR.R = near-infrared spectroscopy in reflectance mode; FT-NIR.R = Fourier-transform mid-infrared spectroscopy in reflectance mode.

${ }^{3}$ Coefficient of determination in cross-validation.

${ }^{4}$ Root mean square error in cross-validation. 
Table 12. Effectiveness of infrared spectroscopy to correctly group samples of different matrixes (cheese, butter, curd, milk powder, and yogurt)

\begin{tabular}{|c|c|c|c|c|c|}
\hline $\begin{array}{l}\text { Infrared } \\
\text { technology }\end{array}$ & Infrared region & Cluster & Model $^{2}$ & $\begin{array}{c}\text { Correct } \\
\text { classification, } \\
\%\end{array}$ & Reference \\
\hline \multicolumn{6}{|l|}{ Cheese } \\
\hline NIR.R & $1,100-2,000 \mathrm{~nm}$ & $\begin{array}{l}\text { Mixture proportion of cow, } \\
\text { goat, and sheep milk }\end{array}$ & ANN-PCA & 50 & Soto-Barajas et al., 2013 \\
\hline VIS-NIR.R & $400-2,500 \mathrm{~nm}$ & $\begin{array}{l}\text { Cow feeding (pasture or } \\
\text { preserved forage) }\end{array}$ & PLS-DA & 96 & Andueza et al., 2013 \\
\hline \multicolumn{6}{|l|}{ Butter } \\
\hline FT-MIR.ATR & $4,000-700 \mathrm{~cm}^{-1}$ & Conventional vs. organic & SIMCA & 100 & Plans Pujolras et al., 2015 \\
\hline FT-.MIR.ATR & $4,000-600 \mathrm{~cm}^{-1}$ & Region of origin & PLS-DA & 100 & Bassbasi et al., 2014 \\
\hline \multicolumn{6}{|l|}{ Curd } \\
\hline FT-NIR.R & $4,000-10,000 \mathrm{~cm}^{-1}$ & Storage temperature & DA & $83-100$ & Králová et al., 2014 \\
\hline FT-NIR.R & $4,000-10,000 \mathrm{~cm}^{-1}$ & Storage week & $\mathrm{DA}$ & $91.2-100$ & Králová et al., 2014 \\
\hline \multicolumn{6}{|l|}{ Milk powder } \\
\hline \multicolumn{6}{|l|}{ Yogurt } \\
\hline FT-NIR.R & $4,000-12,000 \mathrm{~cm}^{-1}$ & Protein adulteration & OC-PLS & $85-90$ & Xu et al., 2013 \\
\hline
\end{tabular}

${ }^{1}$ FT-MIR.ATR $=$ Fourier-transform mid-infrared spectroscopy with attenuated total reflectance; FT-NIR.R = Fourier-transform near-infrared spectroscopy in reflectance mode; NIR.R = near-infrared spectroscopy in reflectance mode; VIS-NIR.R = visible- and near-infrared spectroscopy in reflectance mode.

${ }^{2} \mathrm{ANN}-\mathrm{PCA}=$ artificial neural networks with principal component analysis; PLS-DA $=$ partial least squares discriminant analysis; OC-PLS $=$ 1-class partial least squares regression; $\mathrm{SIMCA}=$ soft independent modeling of class analogy; DA $=$ discriminant analysis.

Table 13. Figures of merit for the prediction models of CLA, total trans-fatty acid, and palm oil using Fourier-transform mid-infrared spectroscopy with attenuated total reflectance spectra in butterfat, butter, and cheese

\begin{tabular}{|c|c|c|c|c|c|}
\hline Trait & Matrix & $\begin{array}{c}\text { Limit of } \\
\text { detection, \% }\end{array}$ & $\begin{array}{c}\text { Limit of } \\
\text { quantification, } \%\end{array}$ & $\begin{array}{l}\text { Sensitivity, } \\
\%^{-1}\end{array}$ & Reference \\
\hline $\mathrm{CLA}$ & Butterfat & 0.179 & 0.537 & 0.0012 & Plans Pujolras et al., 2015 \\
\hline CLA & Butter & 0.218 & 0.653 & 0.0010 & Plans Pujolras et al., 2015 \\
\hline Total trans-fatty acid & Butterfat & 0.183 & 0.549 & 0.0012 & Plans Pujolras et al., 2015 \\
\hline Total trans-fatty acid & Butter & 0.168 & 0.503 & 0.0013 & Plans Pujolras et al., 2015 \\
\hline Palm oil & Butter & 3 & 9.8 & 0.0029 & Cuibus et al., 2015 \\
\hline Pam oil & Cheese & 2.8 & 9.6 & 0.03 & Cuibus et al., 2014 \\
\hline Acid whey & Milk powder & $1.89-2.71$ & - & - & Capuano et al., 2015 \\
\hline Starch & Milk powder & $1.43-1.97$ & - & - & Capuano et al., 2015 \\
\hline Maltodextrin & Milk powder & $1.52-2.10$ & - & - & Capuano et al., 2015 \\
\hline Edible gelatin & Yogurt & 1 & - & - & Xu et al., 2013 \\
\hline Industrial gelatin & Yogurt & 2 & - & - & Xu et al., 2013 \\
\hline Soy protein & Yogurt & 2 & - & - & Xu et al., 2013 \\
\hline
\end{tabular}

accurate technology according to the feature that has to be predicted.

One of the most interesting future dairy applications will be the analysis of whey-derived products and infant formula quality and composition using different spectroscopy techniques; a very recent study on this topic proposed 3 different spectroscopy techniques for quality assessment and control of infant formula and dairy ingredient manufacturing processes (Wang et al., 2018). Finally, efforts should be made to develop universal calibrations considering the wide variability of cheeses and other dairy products that are manufactured by the same company to facilitate their implementation in the industry and to reduce the cost of their maintenance.

\section{REFERENCES}

Aburto, N. J., A. Ziolkovska, L. Hooper, P. Elliott, F. P. Cappuccio, and J. J. Meerpohl. 2013. Effect of lower sodium intake on health: Systematic review and meta-analyses. BMJ 346:f1326.

Andueza, D., C. Agabriel, I. Constant, A. Lucas, and B. Martin. 2013. Using visible or near infrared spectroscopy (NIRS) on cheese to authenticate cow feeding regimes. Food Chem. 141:209-214. 
Aria, M., and C. Cuccurullo. 2017. Bibliometrix: An R-tool for comprehensive science mapping analysis. J. Informetrics 11:959-975.

Bai, Y., J. Xiao, and L. Yu. 2006. Kernel partial least-squares regression. Pages 1231-1238 in The 2006 IEEE International Joint Conference on Neural Network Proc., Vancouver, BC, Canada.

Bassbasi, M., M. De Luca, G. Ioele, A. Oussama, and G. Ragno. 2014. Prediction of the geographical origin of butters by partial least square discriminant analysis (PLS-DA) applied to infrared spectroscopy (FTIR) data. J. Food Compos. Anal. 33:210-215.

Bonjour, J.-P., L. Guéguen, C. Palacios, M. J. Shearer, and C. M. Weaver. 2009. Minerals and vitamins in bone health: the potential value of dietary enhancement. Br. J. Nutr. 101:1581-1596.

Botelho, B. G., B. A. P. Mendes, and M. M. Sena. 2013. Development and analytical validation of robust near-infrared multivariate calibration models for the quality inspection control of Mozzarella cheese. Food Anal. Methods 6:881-891.

Botosoa, E. P., and R. Karoui. 2013. Characterisation of Emmental cheeses within different brand products by combining infrared and fluorescence spectroscopies. Food Bioprocess Technol. 6:2365-2375.

Buing-Pfaue, H. 2003. Analysis of water in food by near infrared spectroscopy. Food Chem. 82:107-115.

Capuano, E., R. Boerrigter-Eenling, A. Koot, and S. M. Van Ruth. 2015. Targeted and untargeted detection of skim milk powder adulteration by near-infrared spectroscopy. Food Anal. Methods $8: 2125-2134$

Cevoli, C., A. Gori, M. Nocetti, L. Cuibus, M. F. Caboni, and A. Fabbri. 2013. FT-NIR and FT-MIR spectroscopy to discriminate competitors, non compliance and compliance grated Parmigiano Reggiano cheese. Food Res. Int. 52:214-220.

Chen, H., C. Tan, Z. Lin, and T. Wu. 2017. Detection of melamine adulteration in milk by near-infrared spectroscopy and one-class partial least squares. Spectrochim. Acta A Mol. Biomol. Spectrosc. 173:832-836.

Chen, H., C. Tan, Z. Lin, and T. Wu. 2018. Classification and quantitation of milk powder by near-infrared spectroscopy and mutual information-based variable selection and partial least squares. Spectrochim. Acta A Mol. Biomol. Spectrosc. 189:183-189.

Chitra, J., M. Ghosh, and H. N. Mishra. 2016. Rapid quantification of cholesterol in dairy powders using fourier transform near infrared spectroscopy and chemometrics. Food Control 78:342-349.

Coppa, M., A. Revello-Chion, D. Giaccone, A. Ferlay, E. Tabacco, and G. Borreani. 2014. Comparison of near and medium infrared spectroscopy to predict fatty acid composition on fresh and thawed milk. Food Chem. 150:49-57.

Cuibus, L., R. Maggio, V. Mureșan, Z. Diaconeasa, F. Fetea, and C. Socaciu. 2014. Preliminary discrimination of cheese adulteration by FT-IR spectroscopy. Bull. UASVM Food Sci. Technol. $71: 2344-2344$.

Cuibus, L., R. Maggio, V. Mureșan, Z. Diaconeasa, O. L. Pop, and C. Socaciu. 2015. Preliminary discrimination of butter adulteration by ATR-FTIR spectroscopy. Bull. UASVM Food Sci. Technol. 72:70-76.

Currò, S., C. L. Manuelian, M. Penasa, M. Cassandro, and M. De Marchi. 2017. Technical note: Feasibility of near infrared transmittance spectroscopy to predict cheese ripeness. J. Dairy Sci. 100:8759-8763.

De Marchi, M., V. Toffanin, M. Cassandro, and M. Penasa. 2014. Invited review: Mid-infrared spectroscopy as phenotyping tool for milk traits. J. Dairy Sci. 97:1171-1186.

EU (European Union). 2011. Regulation (EU) No 1169/2011 of the European Parliament and of the council of 25 October 2011 on the provision of food information to consumers, amending Regulation (EC) No 1924/2006 and (EC) No 1925/2066 of the European Parliament and of the Council and Off. J. Eur. Union L 304.

Fagan, C. C., and C. P. O'Donnell. 2007. Application of mid-infrared spectroscopy to food processing systems. Pages 119-142 in Nondestructive Testing of Food Quality. J. Irudayaraj and C. Reh, ed. Blackwell Publishing, Oxford, UK.

FAO. 2013. Milk and Dairy Products in Human Nutrition. E. Muehlhoff, A. Bennett, and D. McMahon, ed. FAO, Rome, Italy.
FSA (Food Standards Agency). 2016. Foods High in Fat and Foods and Drinks High in Sugar. Accessed May 9, 2016. http://www.food .gov.uk/northern-ireland/nutritionni/healthy-catering/caterers -tips/high.

Gaucheron, F. 2005. The minerals of milk. Reprod. Nutr. Dev. 45:473483.

González-Martín, I., J. M. Hernández-Hierro, C. González-Pérez, I. Revilla, A. Vivar-Quintana, and I. Lobos Ortega. 2014. Potential of near infrared spectroscopy for the analysis of volatile components in cheeses. Lebensm. Wiss. Technol. 55:666-673.

Grassi, S., C. Alamprese, V. Bono, C. Picozzi, R. Foschino, and E. Casiraghi. 2013. Monitoring of lactic acid fermentation process using Fourier transform near infrared spectroscopy. J. Near Infrared Spectrosc. 21:417-425.

Griffiths, P. R. 2010. Theory and instrumentation for vibrational spectroscopy. Pages 31-46 in Applications of Vibrational Spectroscopy to Food Science. J. M. Chalmers, P. Griffiths, and E. Li Chan, ed. Wiley, Chichester, UK.

Holroyd, S. E. 2013. Review: The use of near infrared spectroscopy on milk and milk products. J. Near Infrared Spectrosc. 21:311-322.

Iwamoto, M., S. Kawano, and Y. Ozaki. 1995. An overview of research and development of near infrared spectroscopy in Japan. J. Near Infrared Spectrosc. 3:179-189.

Kraggerud, H., T. Næs, and R. K. Abrahamsen. 2014. Prediction of sensory quality of cheese during ripening from chemical and spectroscopy measurements. Int. Dairy J. 34:6-18.

Králová, M., Z. Procházková, V. Svobodová, E. Mařicová, B. Janštová and L. Vorlová. 2014. Discriminant analysis of Olomouc curd cheese by Fourier transform near infrared spectroscopy. Czech J. Food Sci. 32:31-36.

Lim, J., G. Kim, C. Mo, M. S. Kim, K. Chao, J. Qin, X. Fu, I. Baek, and B. Cho. 2016. Detection of melamine in milk powders using near-infrared hyperspectral imaging combined with regression coefficient of partial least square regression model. Talanta 151:183-191

Lin, P., Y. M. Chen, Y. He, G. W. Hu, X. L. Fu, and C. L. Gu. 2014. Study on nonlinear multivariate methods combined with the visible near-infrared spectroscopy (Vis/NIRS) technique for detecting the protein content of cheese. Food Bioprocess Technol. $7: 3359-3369$

Loudiyi, M., and A. Aït-Kaddour. 2018. Delineation of salts, ripening and gentle heating effects on molecular structure of Cantal-type cheese by mid-infrared spectroscopy. Food Res. Int. 105:221-232.

Lucas, A., D. Andueza, A. Ferlay, and B. Martin. 2008. Prediction of fatty acid composition of fresh and freeze-dried cheeses by visiblenear-infrared reflectance spectroscopy. Int. Dairy J. 18:595-604.

Madalozzo, E. S., E. Sauer, and N. Nagata. 2015. Determination of fat, protein and moisture in ricotta cheese by near infrared spectroscopy and multivariate calibration. J. Food Sci. Technol. 52:1649-1655

Manuelian, C. L., S. Currò, M. Penasa, M. Cassandro, and M. De Marchi. 2017a. Prediction of minerals, fatty acid composition and cholesterol content of commercial cheeses by near infrared transmittance spectroscopy. Int. Dairy J. 71:107-113.

Manuelian, C. L., S. Currò, G. Visentin, M. Penasa, M. Cassandro, C. Dellea, M. Bernardi, and M. De Marchi. 2017b. Technical note: At-line prediction of mineral composition of fresh cheeses using near-infrared technologies. J. Dairy Sci. 100:6084-6089.

Margolies, B. J., and D. M. Barbano. 2018. Determination of fat, protein, moisture, and salt content of Cheddar cheese using midinfrared transmittance spectroscopy. J. Dairy Sci. 101:924-933.

McDermott, A., M. D. Marchi, D. P. Berry, G. Visentin, M. A. Fenelon, N. Lopez-Villalobos, and S. McParland. 2017. Cow and environmental factors associated with protein fractions and free amino acids predicted using mid-infrared spectroscopy in bovine milk. J. Dairy Sci. 100:6272-6284

McDermott, A., G. Visentin, M. De Marchi, D. P. Berry, M. A. Fenelon, P. M. O'Connor, O. A. Kenny, and S. McParland. 2016. Prediction of individual milk proteins including free amino acids in bovine milk using mid-infrared spectroscopy and their correlations with milk processing characteristics. J. Dairy Sci. 99:3171-3182. 
McKenna, D. 2001. Measuring moisture in cheese by near infrared absorption spectroscopy. J. AOAC Int. 84:623-628.

Meagher, L. P., S. E. Holreyd, D. Illingworth, F. van de Ven, and S. Lane. 2007. At-line near-infrared spectroscopy for prediction of the solid fat content of milk fat from New Zealand butter. J. Agric. Food Chem. 55:2791-2796.

Miller, G. D., J. K. Jarvis, and L. D. McBean. 2007. Nutrients Contribution of Milk and Dairy Products. 3rd ed. CRC Press, Boca Raton, FL.

Mlček, J., K. Šustová, O. Rop, T. Juríková, P. Humpolíček, and Š. Balla. 2013. Rapid assessment of selected free amino acids during Edam cheese ripening by near infrared spectroscopy. Acta Vet. Brno 82:191-196.

Niero, G., G. Visentin, S. Ton, M. De Marchi, M. Penasa, and M. Cassandro. 2016. Phenotypic characterisation of milk technological traits, protein fractions, and major mineral and fatty acid composition of Burlina cattle breed. Ital. J. Anim. Sci. 15:576-583.

Nurrulhidayah, A. F., A. Rohman, I. Amin, M. Shuhaimi, and A Khatib. 2013. Analysis of chicken fat as adulterant in butter using Fourier transform infrared spectroscopy and chemometrics. Grasas Aceites 64:349-355.

O'Donnell, C., C. C. Fagan, and P. J. Cullen. 2014. Process Analytical Technology for the Food Industry. Springer, New York, NY.

Plans Pujolras, M., H. Ayvaz, M. L. Shotts, R. A. Pittman, S. Herringshaw, and L. E. Rodriguez-Saona. 2015. Portable infrared spectrometer to characterize and differentiate between organic and conventional bovine butter. J. Am. Oil Chem. Soc. 92:175-184.

R Core Team. 2018. R: A language and environment for statistical computing. R Foundation for Statistical Computing, Vienna, Austria.

Revilla, I., M. I. González-Martín, A. M. Vivar-Quintana, M. A. Blanco-López, I. A. Lobos-Ortega, and J. M. Hernández-Hierro. 2016. Antioxidant capacity of different cheeses: Affecting factors and prediction by near infrared spectroscopy. J. Dairy Sci. 99:5074-5082.

Rosipal, R., and L. J. Trejo. 2002. Kernel partial least squares regression in reproducing Kernel Hilbert Space. J. Mach. Learn. Res. 2:97-123.

Simopoulos, A. P. 2002. The importance of the ratio of omega-6/ omega-3 essential fatty acids. Biomed. Pharmacother. 56:365-379.
Soto-Barajas, M. C., M. I. González-Martín, J. Salvador-Esteban, J. M. Hernández-Hierro, V. Moreno-Rodilla, A. M. Vivar-Quintana, I. Revilla, I. L. Ortega, R. Morón-Sancho, and B. Curto-Diego. 2013. Prediction of the type of milk and degree of ripening in cheeses by means of artificial neural networks with data concerning fatty acids and near infrared spectroscopy. Talanta 116:50-55.

Soyeurt, H., P. Dardenne, F. Dehareng, G. Lognay, D. Veselko, M. Marlier, C. Bertozzi, P. Mayeres, and N. Gengler. 2006. Estimating fatty acid content in cow milk using mid-infrared spectrometry. J. Dairy Sci. 89:3690-3695.

Walther, B., A. Schmid, R. Sieber, and K. Wehr. 2008. Cheese in nutrition and health. Dairy Sci. Technol. 88:389-405.

Wang, X., C. Esquerre, G. Downey, L. Henihan, D. O'Callaghan, and C. O'Donnell. 2018. Assessment of infant formula quality and composition using Vis-NIR, MIR and Raman process analytical technologies. Talanta 183:320-328.

WHO (World Health Organization). 2015. WHO | Healthy Diet. Accessed May 9, 2016. http://www.who.int/mediacentre/factsheets/ fs394/en/.

Williams, P. 2014. Tutorial: The RPD statistic: A tutorial note. NIR news 25:22-26.

Xu, L., S.-M. Yan, C.-B. Cai, Z.-J. Wang, and X.-P. Yu. 2013. The feasibility of using near-infrared spectroscopy and chemometrics for untargeted detection of protein adulteration in yogurt: removing unwanted variations in pure yogurt. J. Anal. Methods Chem. 2013:201873.

Ye, M. P., R. Zhou, Y. R. Shi, H. C. Chen, and Y. Du. 2017. Effects of heating on the secondary structure of proteins in milk powders using mid-infrared spectroscopy. J. Dairy Sci. 100:89-95.

Zamberlin, Š., N. Antunac, J. Havranek, and D. Samaržija. 2012. Mineral elements in milk and dairy products. Mljekarstvo 62:111-125.

Zhao, M., R. J. Beattie, A. M. Fearon, C. P. O'Donnell, and G. Downey. 2015. Prediction of naturally-occurring, industrially-induced and total trans fatty acids in butter, dairy spreads and Cheddar cheese using vibrational spectroscopy and multivariate data analysis. Int. Dairy J. 51:41-51. 